leeward of the proposed road quarry at Herne Bay were considered. The Trinity Corporation would be affected in reference to the defences of the Reculvers-the two spires of the ancient church having been maintained by them for many years as sea marks with stone slopes and groynes for the protection of the cliff. From the fact of their being to the eastward of Herne Bay they may be said to be to windward of the site, still the hastening of the recession at Herne Bay, which has from natural causes alone increased in a marked degree of late, would tend to increase the projection and consequent exposure at the Reculvers.

Next we have the entire landowning interest of the Isle of Sheppy affected by this Canterbury decision, for its northern seaboard retreats at a rapid rate, evidenced by the recent removal of Warden Church, which had been left on the extreme verge of the cliff, due to the extensive slips in the London clay to the westward, which must of course be aggravated if the natural barrier formed by the sea at the base of the cliff is weakened by cutting off the supply coming from the eastward, tending always in its normal state to travel onwards to increase Garrison Point at Sheerness at the outfall of the Medway.

Lastly we have the whole Mile Town and Sheerness frontages affected, where the Government have erected from time to time sea-walls and groynes for the collection of this very beach that the Canterbury magistrates covet for the repairs of their roads. Nor is Sheerness alone affected, but the Queenborough district also, as was evidenced in the great tide of February, I79r, when the whole of the marsh forming the north-west promontory of the Isle of Sheppy was under water, and great loss and damage sustained.

Canvey Island, on the opposite Essex shore, suffered in a similar manner at the same time.

For some years past this practice of removing littoral gravel has been stopped on the Kentish southern coast since Mr. Redman reported for the War Office on the condition of the beaches at Sandown, Deal, Walmer, Dover, Eastbourne, \&c., who strongly urged the suicidal nature of the practice, since which the Government and local authorities have had notice-boards planted along the beach imperatively forbidding the removal of shingle.

This general leeward movement of shore detritus, due to the prevailing wind waves, has been of late years so clearly demonstrated by the authorities cited, and accepted generally by marine engineers, that it appears strange to find editorial articles for months in a magazine of wide circulation dealing with engineering science which resuscitate the old and exploded theories on the question which are to be found in early geological works, and these articles, if not accepted, have at least remained hitherto apparently unchallenged.

We would sum up this perhaps somewhat lengthy review of a topic, of no mean importance however, having reference to our insular position, by saying that the passage of the heavier particles (the shingle) of a marine mound or natural mole is due universally to the action of the waves, although attributed by many early geological writers to the ocean currents-and its influence on the tidal harbours of our shores, is very important.

The masses of shingle are heaped up coincident in direction with the waves which sort the material in regular gradation; an alternate renewal and withdrawal, due to change of wind, produces a resultant leeward motion due to the wind the particular coast is most exposed to, and the largest pebbles in all these marine alluvion are universally accumulated on the summit, and to leeward of the prevailing winds, due to their greater momentum and to their being less influenced by the recoil wave, compared with sand and the smaller stones.

At the last meeting of the South-Eastern Railway Company we find the chairman (Sir E. W. Watkin, M.P.) stating in reference to the proposed Lydd Railway and the line to Dungeness, that it not only would secure in the future the shortest route to the Continent, but that it also gave them access to an important bed of shingle, from the sale of which they anticipated great benefit! and that they saw their way to do a large trade in its conveyance. It was important for road-making, railway-ballasting, and concrete foundations and walls.

This is the not over scrupulous view of the chairman of a leading railway company of one of the most important natural breakwaters on the south-eastern coast, and the uses to which it may be applied as a quarry for the benefit of his company.

The great land-slip which left Warden Church on the verge of the cliff, causing its ultimate recent removal, occurred in September, 1859, and this had been preceded by a similar great fall to the westward about the year 1856 , that of 1859 being in effect a prolongation or extension of the earlier one towards the eastern end of the island. The falls are the result of a gradual subsidence occupying some hours, due to the thorough saturation of the London clay by land drainage down several small chines, and the effect of atmosphere and weather on the face of the cliffs and their degradation at the base by the sea during spring-tides. In effect a broad belt of land moves seaward (not a mere abrasion or undermining of the cliff alone), settles vertically downwards, or spreads out, and slides seawards, presenting a new cliff landward at the last parallel fissure, the moving mass attaining a state of rest in the shape of an under-cliff, with a series of parallel terraces rising and falling in the valley of the fall, with the turf and vegetation undisturbed; and the foreshore and shingle are ploughed up by the fall, forming a kind of "moraine" at the base. After a fall the ordinary waste goes on at an average rate of one yard per annum. Some of the trees near the church had settled down bodily on the prisms of earth to which they were attached, some fifty feet lower in level than when they were in situ, showing how gradual and vertical had been the subsidence.

The question arises, To what extent are the cliffs in the Tertiary formations saturated or affected by percolation through fissures from the sea, and how far this may be the first cause? There are no appearances of land springs from the cliff face. The whole appears to have squeezed down into a saturated or partly fluid base. The rapid degradation of the Sheppy cliffs was pointed out in an article in the St. James's Gazette of May 23, and the absence of any attempts to arrest it. But this constan loss has been eloquently described by Lyell in his great work, "The Principles of Geology," affording as it does a constant supply to the fluctuating foreshores of the River Thames carried up by the superior power of the flood compared with its ebb tide, and brought down again by the prolonged duration of the ebb, aided by upland waters in steps downwards.

\section{SCIENCE AT ETON}

$\triangle$ LTHOUGH Eton still ranks as a purely classical school, and has not established a modern side as her rival Harrow has done, yet the study of science is pursued within her walls to an extent which-in some respects at least-is unequalled at any other school. The numbers of the school vary somewhat on each side of 000 boys, about 120 of whom, constituting the Fourth Form, do no science. About seventy boys more from the Fifth Form make up the Army Class, and do no Science unless they take in Physical Geography and Geology for their final examination. But in the Remove and in the greater part of the Fifth Form, which constitutes the chief mass of the school, two lessons a week in science enter into the regular work of each division.

At the present time the Head-Master has twenty-two Classical Assistants, and the Lower Master two. There are nine Mathematical Masters, and four for science, two 
of whom also give a little help in the mathematical, and one in the literary teaching. On emerging from the Fourth Form a boy spends a year in Remove, during which his two weekly science lessons are devoted to Physical Geography (Erdkunde). Passing on into the Lower Division of the Fifth Form, he is taught the elements of Mechanics, treated experimentally; and during the next year, spent in "Middle Division," he is occupied with Heat, including the principles of the steam-engine. Except in the case of the Army Class, therefore, science is compulsory during three years of every boy's school life. When he enters the Upper Division of the Fifth Form he may drop science altogether, and devote the two lessons a week to additional mathematics. If he does not do this he has his choice between Chemistry, Geology, Physical Geography, and Biology. Many boys leave the school without reaching any higher stage than this ; but those who pass on into the "First Hundred" can either give up science in favour of mathematics or of some literary subject, or, on the other hand, they may take up a second scientific subject, and get an additional two lessons a week. During the present School-time they can select from Chemistry (Metals), Physics (Light), Geology (Elementary and Advanced), Physiography, Botany, and Physiology (Muscle and Nerve). Hence a boy who enters Remove at thirteen and stays at Eton until he is nineteen, has the opportunity of acquiring a considerable amount of elementary scientific knowledge. He hears two lectures a week and writes out an abstract of them which is looked over and corrected. His progress is tested by written examinations, the frequency of which depends upon the master he is "up to." Oral

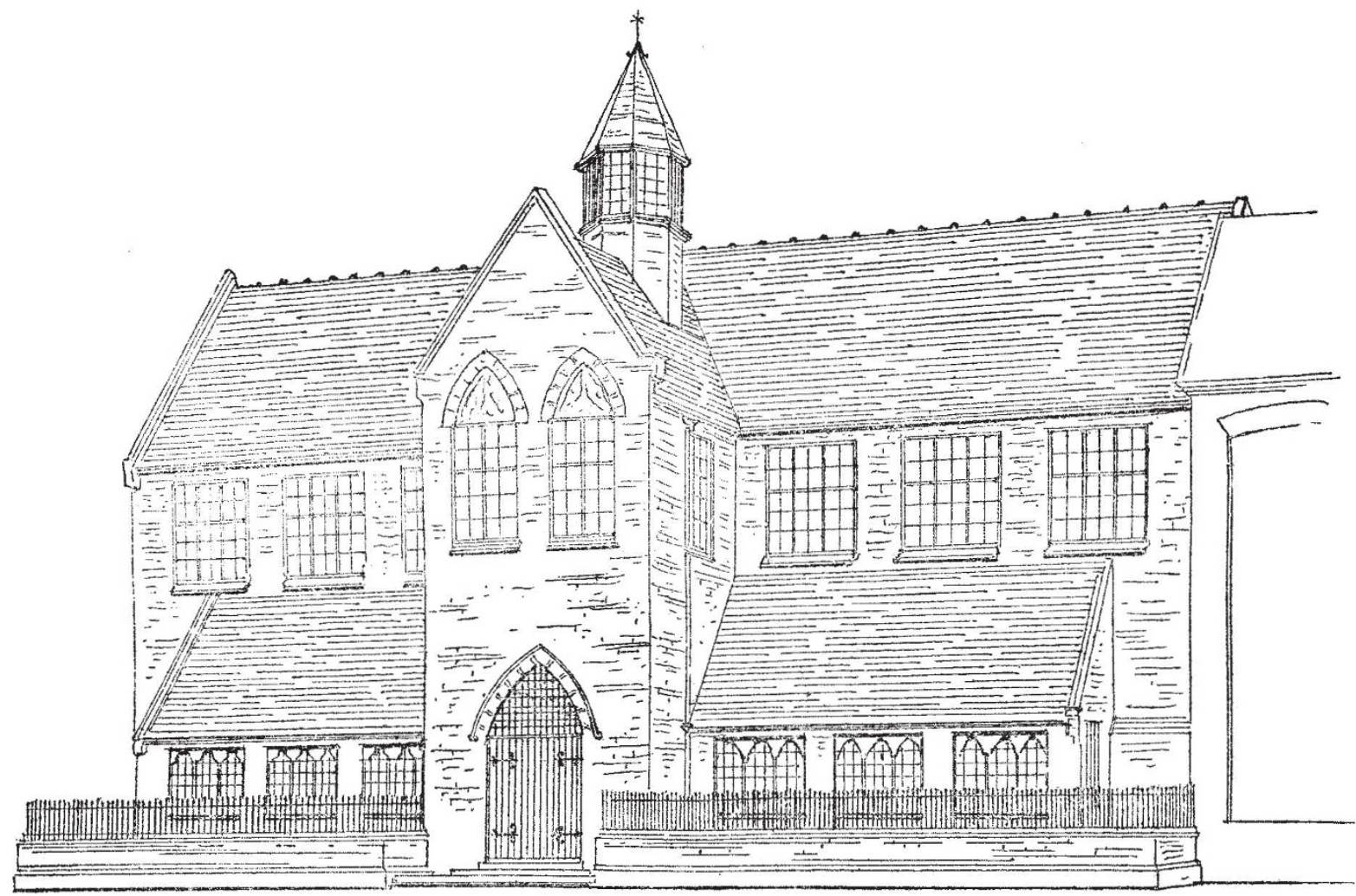

VIEW - OF-SOUTH - FRONTW -

examination is rarely possible except in the upper parts of the school, owing to the necessarily large size of the classes.

At the examinations for promotion which occur every Half, though they are annual as regards individual boys, science is allotted from one-tenth to one-twelfth of the total marks. Although it is not a "pluck subject" like mathematics, yet many a boy who has failed by a few marks in his "general total" regrets not having paid more attention to his science lectures, which would have enabled him to make up the deficit; and the effect is often visible in the improvement in his abstracts during the next School-time.

Besides the compulsory science, which is a part of the regular school-work, many boys devote three or four hours of their spare time every week to some form of practical scientific work. Most of them are preparing themselves to try for the prizes given annually by the
Governing Body for Chemistry and Physics, Geology and Physical Geography, and Biology respectively. A chemical laboratory, with accommodation for twentyeight boys at once, has been in use for some years. It owes its existence in great part to the liberality of the present Head-Master, Dr. Hornby, some of the Assistant Masters, and some old Etonians. The laboratory and chemical lecture-room, together with a private laboratory, apparatus-room, store-rooms, \&c., form a handsome building in Keate's Lane. Opposite to it is the Round School, formerly used for mathematical teaching, and now converted into a museum. It contains a fine collection of British birds made by the late Provost of King's College, Cambridge, Dr. Thackeray, and presented by him to the school. Some of the specimens are valuable, owing to their being mentioned by Yarrell. There is also a good collection of Lepidoptera made by a former pupil of the school, and presented by his parents after his untimely 
death, within two years of his leaving Eton. A tolerably complete series of recent shells has been obtained, and a collection of the more important zoological types is in process of formation. Geology is represented by a fair series of British rocks and fossils, and by remains of the mammoth, hippopotamus, reindeer, and Bos primigenius, from the river gravels of the neighbourhood, together

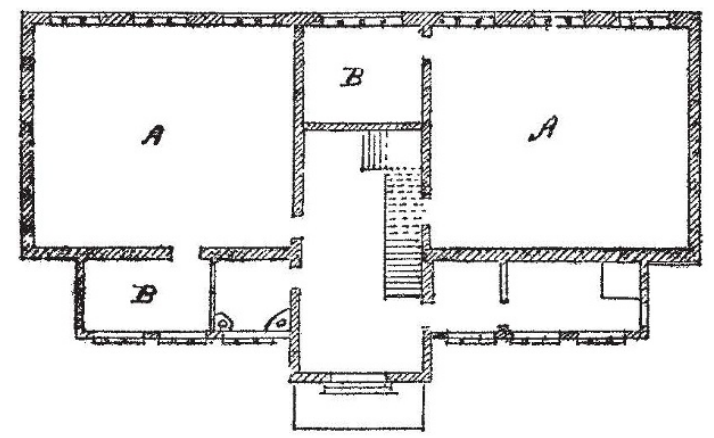

- GROUND-PLAN - with flint implements and neolithic axe-heads which have been dredged out of the river. There are also a few cases of specimens illustrative of volcanic and glacial action, and of the more important processes of Metallurgy, pottery, \&c.

Beyond the laboratory, and separated from it by the racquet-courts, are the new Science Schools, which are

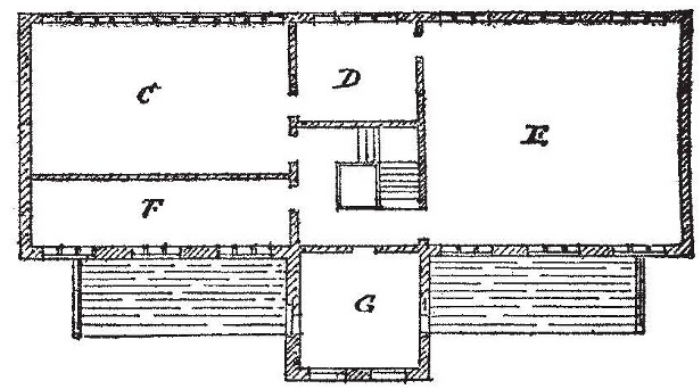

- FIRST-FLOOR-PLAN-

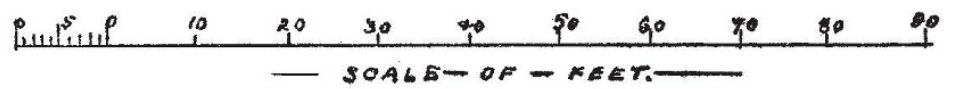

being used this Half for the first time, three out of the four Science Masters having been hitherto accommodated in some discarded mathematical schoolrooms. On the ground floor there are two schoolrooms (A, A), each accommodating forty boys, and two preparation-rooms $(\mathrm{B}, \mathrm{B})$ opening into them, besides furnace-room, lavatory, \&c. On the first floor are the biological laboratory (C), preparation-room (D), and schoolroom (E), all en suite, together with a general apparatus-room (F) and stores room $(G)$. The laboratory, which is 28 feet by 16 feethas accommodation for seventeen boys at once, the table, running alon the length of the room, so that the workers shall face the window. Except for the necessary supports, this is continuous along almost the whole of one side of

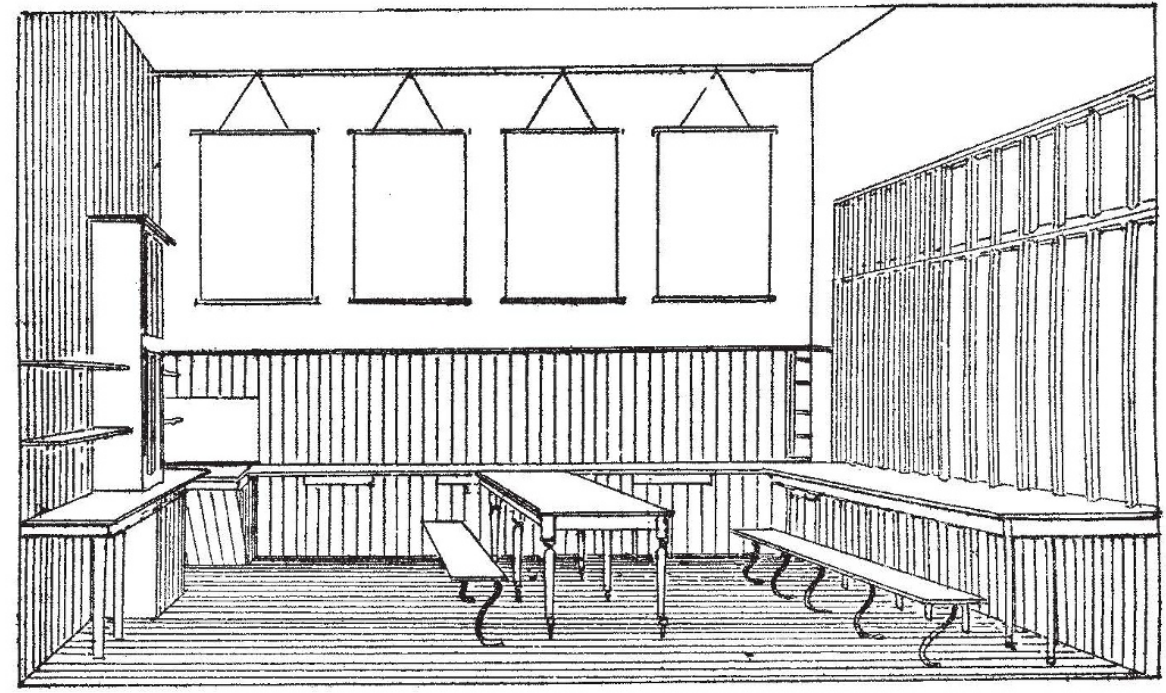

the room. The other side is occupied by shelves and a large cupboard, half of which is divided up into compartments, one for each boy. A sink, a bookshelf, and a large slate occupy three of the corners, the door being at the fourth. The rooms are all panelled with stained deal to a height of about 5 feet from the floor, which leaves ample space for diagrams above.

The building has been designed and erected by Mr. E.
Aborn of Eton, at the cost of the Governing Body of the College, of which Prof. Huxley became a member rather more than a year ago as the representative of the Royal Society. At the request of his colleagues he provided Mr. Aborn with a statement of what he thought was required for the proper accommodation of the three houseless Science Masters, and the result is the eminently practical but inexpensive building, with which all who 
use it, both boys and masters, are alike pleased. The schoolrooms are the best in the College as regards light and accommodation for teachers and taught, and offer a striking contrast to the dark and uncomfortable rooms which were built a few years ago for the Mathematical Masters.

Besides providing a home for the science-teaching, the Governing Body have also placed a grant of money at the disposal of the teachers for the purchase of microscopes, diagrams, maps, \&c., so that a boy who is really anxious to learn has plenty of opportunities for so doing. The number is not very large at present, as so many other interests have to be considered, such as the classical work and the games. Those, however, who are really taking up science with a view to University honours, find their tutors less exacting about their classical studies; and that the time spent in the laboratory need not interfere with athletics is shown by the fact that the two boys who last year divided the Governing Body's prize for Biology are both distinguished football players. One of them was a prominent member of the school football eleven during the past winter, and has this year rowed for the fourth time in the Eton crew at Henley Regatta. His numerous official duties as "captain of the boats" during the last two years bave not prevented his acquiring sufficient knowledge to gain him an entrance exhibition for Natural Science at . Oxford, an honour which has only once before been gained by an Etonian.

In addition to the Chemical and Biological Laboratories Eton possesses a well-organised School of Practical Mechanics, consisting of a drawing-room, smithy, and shops for carpentry and metal-working, the whole being under the superintendence of a specially-qualified instructor. Much work is done here out of school-hours, oars, bookcases, cupboards, lathes, and a small steam-engine being some of the practical results of this institution, which is now completing the second year of its existence.

\section{NOTES}

THE death, on Sunday, is announced of Prof. Bruhns, the Director of Leipzig Observatory.

THE greatest activity prevails in the Palais de l'Industrie, preparing for the Exhibition of Electricity, but it is feared that, in spite of all efforts, the day of the formal opening will have to be postponed.

THE Municipal Council of Paris has finally granted to Siemens Brothers the authorisation to place rails in the streets for their electrical railway from the Place de la Concorde to the Exhibition. But no viaduct will be constructed, as formerly contemplated, and the rails will be merely laid flat on the pavement.

Mr. MUndella stated in the House of Commons the other day that Mr. Samuelson, M.P. for Banbury, and Mr. Slagg, M.P. for Manchester, had consented to investigate the whole question of technical education on the Continent at their own expense. Mr. Mundella was in communication with two other gentlemen, who, he hoped, would join the two mentioned.

A. PUBLIC meeting will be held on August 8 at the Society of Arts for the purpose of re-organising the Trades Guild of Learning on a larger basis. Among the supporters of the movement is Sir John Lubbock.

A MeEting was held on Tuesday afternoon at Grosvenor House, Park Lane, to receive and consider a report from the Smoke Abatement Committee on the subject of an exhibition and trials of improved heating and smoke-preventing appliances, to be opened at South Kensington in October next. There was a numerous attendance. The exhibition in question will be held $\mathrm{n}$ the East and West Arcades and in buildings adjoining the
Royal Albert Hall; and gold, silver, and bronze medals, together with certificates of merit, will be awarded upon the report of a special committee. It will be opened on October 24 and closed on November 26. Dr. Siemens moved the first resolution, declaring that the present smoky condition of the atmosphere of London injuriously affects the health and happiness of the community, besides destroying public buildings, deteriorating perishable fabrics, and entailing in various ways unnecessary expenditure. The speech of Dr. Siemens was a powerful argument in support of the principles thus enunciated, and was warmly cheered. Sir Henry Thompson, in seconding the motion, pointed out that the admixture of unburnt fuel in the shape of smoke with the atmosphere must of necessity be prejudicial to those who had the misfortune to breathe it. He also showed by illustration how highly desirable it was on all grounds of health that the air should be perfectly free from smoke. Dr. Quain, Mr. Spencer Wells, and Mr. G. J. Romanes supported the proposition, which was carried unanimously. Other resolutions were carried, and it was resolved by the meeting to support the efforts now being made to reduce the evil arising from coal-smoke, and to assist in raising the funds necessary for constructing and carrying out, on a practical scale, the competitive testing of the various appliances to be shown, and for providing suitable prizes, medals, \&c.

THE new building of the "Deutsche Seewarte" at Hamburg will be inaugurated on September 14. The Emperor William will be present, and will at the same time open a Marine Exhibition connected with the building.

THE annual meeting of the British Medical Association has been delayed a week beyond its usual time in consequence of the Medical Congress meeting in London. It will extend from the 9th till the I th of August, and is to be held at Ryde, Isle of Wight. The address on medicine will be delivered by Dr. J. S. Bristowe of St. Thomas's Hospital, that on surgery by Mr. Jonathan Hutchinson of the London Hospital, and that on obstetric medicine by Dr. J. Sinclair Coghill, visiting physician to the National Hospital for Consumption at Ventnor.

THE Harvard Geological Museum has lately received from the Smithsonian Institution a series of the types of the fossil plants described by Prof. Lesquereux in connection with his various Government publications. Prof. Lesquereux is also engaged in identifying a large collection of fossil plants made by $\mathrm{Mr}$. Sternberg for the museum. The collection contains nearly all the species thus far described from the Cretaceous beds of Western Kansas.

AN exhibition and congress in connection with the culture of vines is appointed to take place in Milan in September next. The congress, which will be composed of experts from various countries, will be charged with the duty of inquiring into the subject of the disease which has of late years rendered the wine crop so uncertain. The exhibition will consist mainly of appliances for the application to vegetation of insect-destroying agencies, of machines and instruments for grafting, of photographs, plates, and printed publications relative to the vine disease, specimens of vine parasites, and numerous other objects serving similar purposes.

AcCording to the Mineral Statistics of Victoria for 1880 the quantity of gold raised in the Colony for the past year was 829,121 oz. 5 dwt., being upwards of $70,173 \mathrm{oz}$. more than in 1879. While there has been a decided increase in the quantity raised in alluvial mines, the main increase has been in the quartz mines, which have yielded 529, 195 oz. The increase in alluvial mines is partly due to the opening-up of new gold-producing areas, and partly to the operations of the diamond drills recently imported. 